\title{
Care of Patients with Diabetic Foot Disease in Oman
}

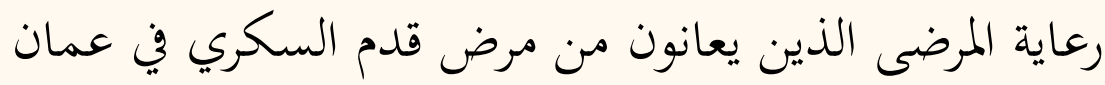

$$
\text { إبراهيم صالح البوسعيدي، نادية نور عبد الهادي، كيرستن كوبيل }
$$

ABSTRACT: Diabetes mellitus is a major public health challenge and causes substantial morbidity and mortality worldwide. Diabetic foot disease is one of the most debilitating and costly complications of diabetes. While simple preventative foot care measures can reduce the risk of lower limb ulcerations and subsequent amputations by up to $85 \%$, they are not always implemented. In Oman, foot care for patients with diabetes is mainly provided in primary and secondary care settings. Among all lower limb amputations performed in public hospitals in Oman between 2002-2013, 47.3\% were performed on patients with diabetes. The quality of foot care among patients with diabetes in Oman has not been evaluated and unidentified gaps in care may exist. This article highlights challenges in the provision of adequate foot care to Omani patients with diabetes. It concludes with suggested strategies for an integrated national diabetic foot care programme in Oman.

Keywords: Diabetes Mellitus, complications; Diabetic Foot; Amputations; Ulcers; Preventive Health Services; Epidemiology; Oman.

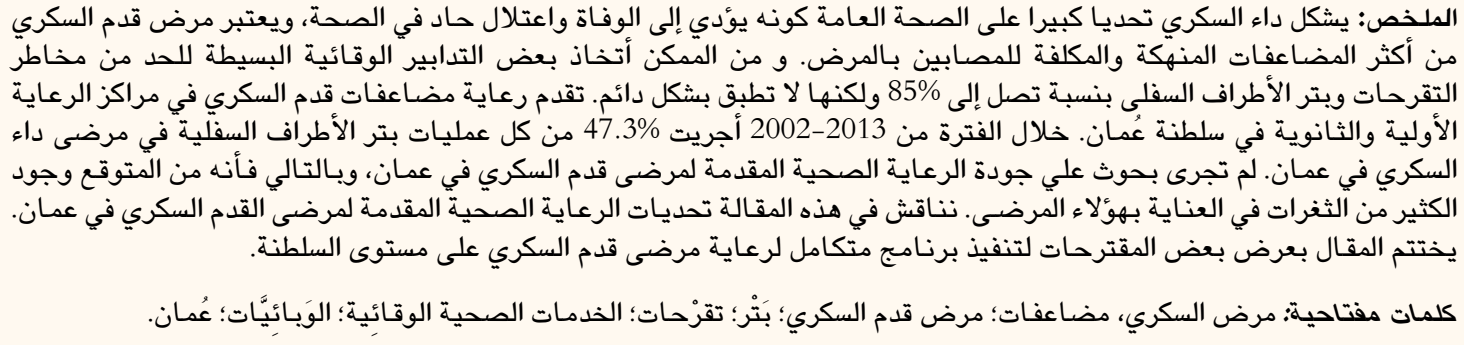

$\mathrm{D}$ IABETES MELlitus IS A CHRONIC DISEASE of worldwide significance. ${ }^{1}$ On a global scale, the prevalence of diabetes has continued to increase steadily, reaching $8.8 \%$ among adults aged 20-79 years old in $2015 .^{2}$ Diabetes is associated with long-term microvascular and macrovascular complications, including diabetic foot disease (DFD) - a group of heterogeneous foot conditions in which peripheral neuropathy and vascular disease, sometimes complicated by infection, may result in foot ulceration and lower limb amputation., ${ }^{3,4}$ Due to its substantial morbidity and mortality, DFD is regarded as a global public health challenge and is considered to be one of the most debilitating complications of diabetes, with severe personal, societal and economic costs. ${ }^{1,3}$ Nevertheless, DFD continues to be inadequately managed by healthcare services in many countries. ${ }^{1}$

Globally, the prevalence of diabetic foot ulcers ranges from $1-12 \%$, with national rates generally higher among Arab countries, from 5\% in Jordan to $12 \%$ in Algeria., 5 Approximately half of all lower limb amputations are due to diabetes, and of these lower limb amputations, active foot ulceration has been found to be a precursor in more than $85 \%$ of cases. ${ }^{3,7}$ In 2015, the reported age-adjusted prevalence of diabetes in Oman was $14.8 \%{ }^{2}$ In response to the rise in diabetes prevalence over the past two decades, diabetes care is currently a priority in the national health programme coordinated by the Omani Ministry of Health $(\mathrm{MOH}){ }^{8,9}$ While advances have been made in the delivery of diabetes care, the prevalence of long-term complications of diabetes, including foot ulceration and lower limb amputation, is expected to rise. ${ }^{9,10}$ A structured well-resourced national programme is therefore vital to prevent and effectively manage DFD in Oman. ${ }^{11}$

The aim of this article was to review diabetesrelated amputations and describe the current status of foot care services among patients with diabetes in 


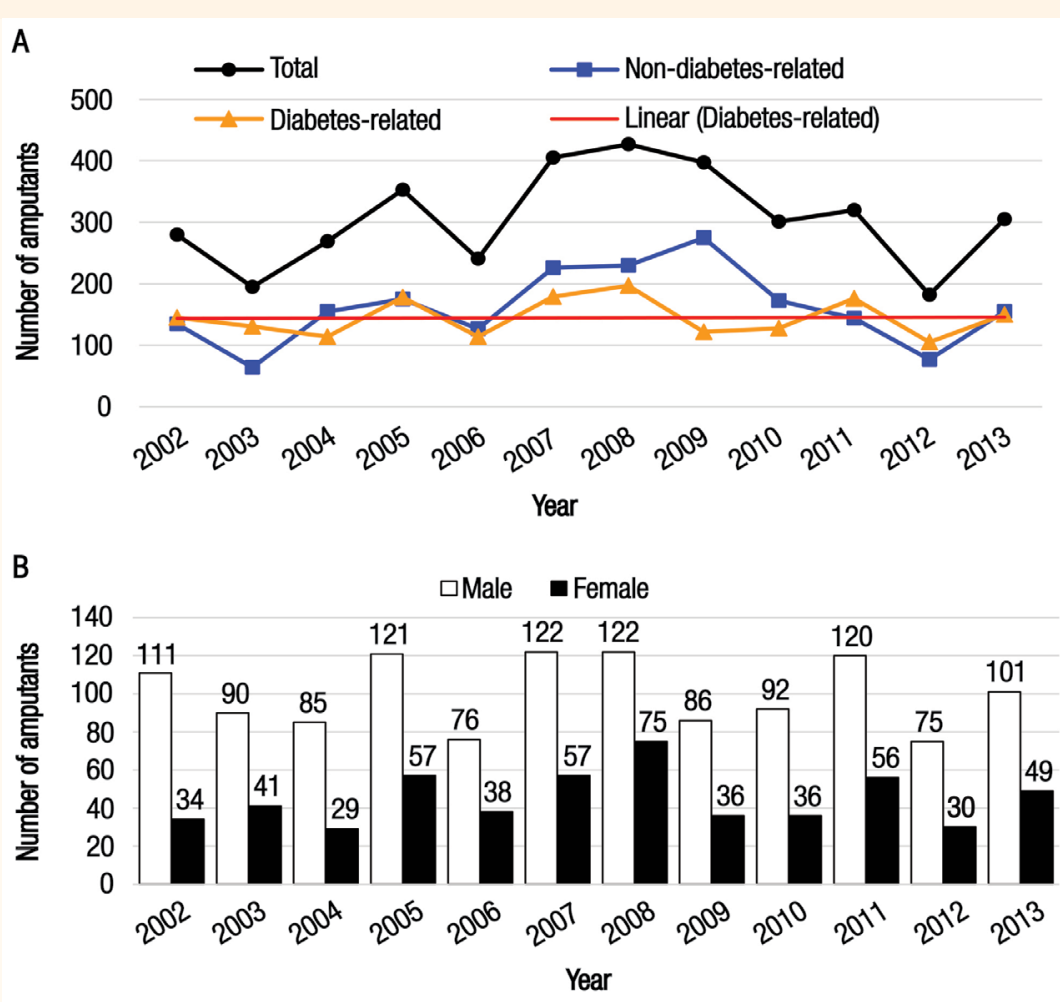

Figure 1A \& B: Trends in (A) overall diabetes- and non-diabetes-related lower limb amputations and (B) diabetes-related lower-limb amputations by gender performed in Ministry of Health institutions in Oman between 2002-2013. ${ }^{13-24}$

Oman. Challenges in the provision of adequate foot care to Omani patients with diabetes are discussed and recommendations drawn from international guidelines are presented in order to improve diabetic foot care in primary and secondary care settings in Oman. Both relevant published and grey literature was reviewed.

\section{Diabetes-Related Lower Limb Amputations}

Despite the burden of diabetes-related lower limb amputations, there is a paucity of research regarding the epidemiology of DFD in Oman, including a lack of published studies exploring the national prevalence of diabetic foot ulcerations and/or lower limb amputations. ${ }^{3,9,11}$ Currently, the only available data on diabetes-related lower limb amputations in Oman are from the $\mathrm{MOH} .{ }^{12-24}$ The reported annual incidence rate of diabetes-related lower limb amputations ranges between $20-36$ per 10,000 patients with diabetes. ${ }^{12}$ Yearly trends in diabetes- and non-diabetes-related lower limb amputations performed in $\mathrm{MOH}$ institutions in Oman are shown in Figure $1 .^{13-24}$ Between 2002-2013, a total of 3,675 lower limb amputations were performed, including 1,739 (47.3\%) diabetesrelated amputations. Additionally, over two-thirds
(69.1\%) of the patients with diabetes were male. ${ }^{13-24}$ In general, the number of lower limb amputations performed on male patients was consistently higher than for females; this finding is consistent with previous studies. ${ }^{25,26}$ However, the overall annual number of diabetes-related amputations was similar throughout the 12 -year period; ${ }^{13-24}$ this observation is inconsistent with recent studies from other countries, which demonstrate an overall decrease in diabetesrelated lower limb amputation rates. ${ }^{25,27,28}$

The generally static annual number of lower limb amputations in Oman may reflect suboptimal foot care among patients with diabetes. ${ }^{13-24}$ However, these data may underestimate the true number of diabetesrelated amputations for several reasons. First, the reported data represent amputations performed in public hospitals only and do not include amputation data from tertiary institutions not managed by the $\mathrm{MOH} .{ }^{13-24}$ Indeed, the number of private hospitals providing surgical services is increasing in Oman. ${ }^{29}$ Second, inaccurate and under-reporting of diabetesrelated data is commonplace in diabetes care. ${ }^{30}$ Third, the number of Omanis seeking medical treatment abroad is increasing. ${ }^{31}$ These factors therefore complicate estimations of the true rate of diabetes-related amputations in Oman. 
Table 1: Levels of foot care required at the national level in the management of diabetic foot disease

\begin{tabular}{|c|c|}
\hline Level of care & Description \\
\hline Level 1 & $\begin{array}{l}\text { General practitioner, podiatrist, and } \\
\text { diabetic nurse }\end{array}$ \\
\hline Level 2 & $\begin{array}{l}\text { Diabetologist, surgeon (general and/or } \\
\text { vascular and/or orthopaedic), podiatrist, } \\
\text { and diabetic nurse }\end{array}$ \\
\hline Level 3 & $\begin{array}{l}\text { Specialized foot centre with multiple } \\
\text { disciplines specialized in diabetic foot care }\end{array}$ \\
\hline \multicolumn{2}{|c|}{$\begin{array}{l}\text { Reproduced with permission from Bakker K, Apelqvist J, Schaper } \\
\text { NC; International Working Group on Diabetic Foot Editorial Board. } \\
\text { Practical guidelines on the management and prevention of the diabetic } \\
\text { foot } 2011.1^{11}\end{array}$} \\
\hline
\end{tabular}

It is widely acknowledged that the implementation of evidence-based preventative and therapeutic foot care strategies can reduce lower limb ulceration rates and subsequent amputations by $45-85 \%$ in patients with diabetes. ${ }^{5,25,27,28}$ Such strategies include optimised glycaemic control, regular foot selfcare, screening/identification of at-risk feet, risk reduction through podiatry, appropriate footwear/ orthotic devices, patient/staff education and multidisciplinary management of DFD cases. ${ }^{5,11,32}$ Surgical interventions-including both prophylactic and revascularisation surgeries-play a role in preventing foot ulceration, improving wound healing and reducing the incidence and site of lower limb amputations. ${ }^{32}$

A successful foot care programme requires a coordinated healthcare system with a multidisciplinary approach. ${ }^{11,32}$ International guidelines recommend that all countries adopt a three-level model of foot care management which should be resourced to provide appropriate foot care services for patients with different levels of risk [Table 1]. ${ }^{11}$ In 1990, the National Diabetes Prevention and Control Programme was established in Oman to tackle the growing burden of diabetes as well as to reduce the rate of long-term diabetes-related complications. ${ }^{9}$ In 2006, the National Programme for Screening of Non-Communicable Diseases was implemented to provide screening services for five chronic conditions (diabetes, hypertension, obesity, hypercholesterolaemia and chronic renal impairment) to all Omanis aged $\geq 40$ years old attending primary health care centres (PHCCs). ${ }^{33}$ However, this latter programme does not screen for diabetes-related complications and there is currently no specific national goal to reduce the burden of DFD in Oman.

\section{PRIMARY CARE}

In Oman, routine foot care is provided mainly in primary care settings at PHCCs as part of overall diabetes care. The diabetes care team consists of a primary care physician or family physician, a diabetes practice nurse and a dietitian. ${ }^{34}$ Local diabetes guidelines mandate primary care professionals perform at least one annual foot examination on all patients with diabetes, including an assessment of skin abnormalities, structural deformities, protective sensation, circulation and footwear., ${ }^{912}$ Patients with foot ulcers are frequently managed by nurses, most of whom are not trained in diabetic foot care. ${ }^{35}$ To date, no detailed national guidelines for the prevention and management of DFD have been published or implemented. However, the $\mathrm{MOH}$ launched several nurse-led clinics in selected catchment areas throughout Oman in 2004 so that patients with diabetic foot ulcers could be initially managed by nurses trained in wound and diabetic foot care. ${ }^{35}$ Situated in PHCCs, the clinics are equipped with basic wound care materials including scalpels, forceps and cotton gauze for basic wound dressing. By December 2013, 25 nurse-led diabetic foot clinics had been established in Oman; however, more are required..$^{35}$

\section{SECONDARY CARE}

Patients with more severe or complicated cases of DFD are referred from PHCCs to secondary care facilities known as polyclinics. ${ }^{34}$ Within these polyclinics, highrisk diabetes clinics and foot care clinics are situated next to each other and operate simultaneously on specific days of the week. In most cases, a multidisciplinary team manages DFD cases, including a diabetologist, dietitian and nurse with training in diabetes and sometimes a podiatrist or wound care nurse in certain cases. Foot care clinics are equipped with some of the equipment and materials required for the diagnosis and management of peripheral vascular disease, peripheral neuropathy and foot ulcers (e.g. Semmes-Weinstein monofilament, 128 Hertz tuning forks, hand-held 5-10 megahertz Doppler probes and advanced wound care products such as charcoal, hydrogels and calcium alginate dressings). However, it is important to note that secondary care diabetic foot care clinics are not available in all areas of Oman due to a lack of local resources, staffing and infrastructure. Furthermore, there is a shortage of other diagnostic and therapeutic resources, such as vibration perception threshold devices, insoles, orthotic and off-loading devices, casting techniques and radiological studies.

\section{Podiatric services}

The role and value of podiatrists in the primary and secondary prevention of DFD is recognised internationally. ${ }^{36}$ Regular access to podiatry services can decrease the prevalence and size of foot callosities, improve foot care knowledge and self-care 
and significantly reduce the risk of foot ulceration recurrence in patients with diabetes. ${ }^{36,37}$ In Oman, podiatrists mainly work as part of multidisciplinary teams in secondary care settings. Unfortunately, there is a severe shortage in the podiatry workforce of Oman; this is common for many countries worldwide, particularly developing countries. ${ }^{24,38}$ Currently, there are 16 podiatrists in the public health system in Oman, of which 13 are based in the capital city of Muscat and the other three are located in the Ad Dakhilyah, Ash Sharqiyah North and Al-Batinah North governorates..$^{35}$ This equates to approximately one podiatrist per 5,000 patients with diabetes in Oman. ${ }^{24}$ Due to this workforce shortage, diabetes podiatry services are essentially limited to the care and management of high-risk patients. Fortunately, the existing shortage of podiatrists in Oman has been recognised by decision-makers-in coordination with the Ministry of Higher Education, the $\mathrm{MOH}$ currently provides scholarships for students to complete their podiatry studies at overseas universities. As of December 2015, there were 10 students (eight undergraduate and two postgraduate) from Oman undergoing podiatry training abroad. ${ }^{35}$

\section{TERTIARY CARE}

Patients who require more specialised diabetic foot management are referred to regional or national centres in Oman where tertiary care is provided. In addition to advanced non-surgical services, tertiary care centres provide surgical interventions for the management of DFD, including wound debridement, revascularisation surgeries and lower limb amputations. ${ }^{35}$ Further details and discussion of the surgical management of DFD cases in Oman is outside the scope of this review.

\section{Diabetic Foot Care Education}

Patient and carer education about DFD risk factors and foot self-care is instrumental in preventing foot ulcers and subsequent amputations. ${ }^{11,32}$ During routine follow-up consultations, diabetes care providers are mandated by local guidelines to provide foot care education. ${ }^{9}$ Although PHCCs in Oman are staffed with qualified professionals, opportunities for patient education are somewhat limited. Currently, no established programmes focus on the delivery of diabetic foot care education. A recent pilot study evaluated the provision of foot care education to 310 Omani diabetic patients attending PHCCs and found that less than $50 \%$ of patients reported receiving education on recommended foot self-care practices and protective footwear. ${ }^{39}$ A number of factors could contribute to suboptimal diabetic foot care education in Oman. First, healthcare professionals are faced with a number of organisational and system-related barriers to effective diabetes care education. These include heavy workloads, language/communication barriers, a perceived lack of teamwork and a shortage in the number of diabetes service providers. ${ }^{40}$ Second, a large proportion of Omani patients with diabetes, especially patients over the age of 50 years, have minimal or no formal education, as access to education was limited prior to the $1970 \mathrm{~s} .{ }^{41}$ Finally, health literacy is poor among people with diabetes in Oman, which is a factor associated with poor diabetes outcomes. ${ }^{42}$

\section{Diabetic Foot Care Training}

Diabetic foot education and wound care training directed at diabetes healthcare providers is equally vital in the prevention and management of DFD. ${ }^{11,32}$ In Oman, few educational facilities provide on-going diabetic foot care training. However, the establishment of the National Diabetic Foot Training Centre in 2012 was the first step in providing nursing staff with the necessary training to manage patients with diabetic foot ulcers. The centre is based in the diabetic foot clinic in Bausher Specialized Polyclinic in Muscat and is staffed with a podiatrist, a wound care nurse specialist and wound management nurses. In addition to being a referral centre for patients with DFD, it provides nurses from all over the country with short training courses in foot examination, basic and advanced wound management and diabetic foot care. However, advances in training healthcare professionals are limited as the centre accommodates only 2-3 trainees per month. As of February 2016, 100 nurses had received training in diabetic foot care, of which 61 work in Muscat. ${ }^{35}$

\section{Recommendations to Improve Diabetic Foot Care in Oman}

Given that diabetes-related foot amputations are largely preventable, there is room for improvement in the delivery of diabetic foot care in Oman. , $^{3,511,32}$ The increasing national prevalence of diabetes highlights the importance of providing sufficient high-quality health services for those with the condition. The following recommendations are suggested to improve diabetic foot care services in Oman.

\section{IMPLEMENTATION OF A NATIONAL PROGRAMME}

Alongside current programmes to manage and prevent diabetes, a national diabetic foot care 
programme needs to be designed and implemented to address system-wide changes required for the prevention and management of DFD.,34 Successful programmes of this kind have been implemented in both poor- and well-resourced countries. ${ }^{43-45}$ The primary goal of this programme should be to reduce diabetes-related lower limb amputations. The Save the Diabetic Foot Project in Brazil is a commendable example of how the implementation of simple and low-cost preventative measures can result in a large reduction in amputation rates among patients with diabetes (77.8\% over nine years).$^{45}$ Taking into account shortages in diabetic foot care services and human resources in Oman, the establishment of a national diabetic foot care programme should occur in phases and be based on time-limited, attainable targets. ${ }^{11}$ Coordination between diabetes care providers and health policymakers is pivotal to facilitate the implementation of such a programme. ${ }^{46}$ In addition, the impact of foot care improvement strategies as part of the programme should be evaluated continuously through a set of process and outcome indicators, such as the completion and outcomes of foot examinations and amputation rates. This type of monitoring will enhance understanding of the epidemiology and burden of DFD in Oman.

\section{PATIENT EDUCATION}

Education programmes for patients with diabetes and their families should be provided to enhance community awareness of DFD and emphasise the importance of optimal diabetes control to prevent complications in general and regular foot self-care practices to prevent foot ulcers in particular. This education needs to be tailored to Oman, as a number of sociocultural factors may put patients with diabetes in Oman at particularly high risk for DFD-for example, many individuals may find it uncomfortable to wear closed shoes and socks due to the characteristically hot and dry weather in Oman; patients with diabetes therefore often continue to wear traditional sandals, which do not offer protection from external trauma. ${ }^{7}$ Given the limited literacy and education among many individuals with diabetes in Oman, the mode of delivery and the content of educational initiatives needs to be simple, repetitive, clearly presented and targeted for education/literacy level and sociocultural practices. ${ }^{41,42}$ Ideally, foot care education, as part of self-management education for patients with diabetes, should be delivered by health educators, nurses or doctors to patients in groups rather than individuals; furthermore, attractive written materials with pictorial diagrams should be used. ${ }^{40-42}$

\section{HEALTH PROFESSIONAL EDUCATION AND TRAINING}

The National Diabetic Foot Training Centre in Muscat should be expanded to provide high-quality diabetic foot care training to a larger number of health professionals. This could be accomplished by increasing training capacity to include primary care physicians, podiatrists and diabetes nurses. Furthermore, regional diabetic foot training centres should be established in each governorate in Oman to equip diabetes care providers with continuous training in the management of patients with DFD. An alternative would be to hold annual workshops on foot examination, identification of at-risk feet and management of foot ulcers for hospital-based and primary care health professionals involved in diabetes care. Moreover, the training should be supported by the development and regular updating of diabetes foot care guidelines.

\section{DIABETIC FOOT CARE RESOURCES AND FACILITIES}

Given the shortage of human resources and health infrastructure in Oman, the set-up of multidisciplinary diabetic foot care teams in primary and secondary care should be done in stages, with various specialist team members introduced gradually. ${ }^{11,24}$ In PHCCs, healthcare teams should consist of a primary care physician, diabetes nurse, health educator and podiatrist. Secondary care-based teams should include a diabetologist, surgeon, podiatrist, diabetes nurse and orthotist. Continuous coordination between policymakers at the $\mathrm{MOH}$ and Ministry of Higher Education in Oman is necessary to increase the numbers of skilled professionals in the labour pool. Moreover, diabetic foot care clinics should be set up throughout the country and equipped with the necessary resources for the management of diabetic foot ulcers, including diagnostic devices, customised footwear and orthotics, offloading devices, casting techniques and imaging studies.

\section{RESEARCH}

Diabetic foot care and DFD research in Oman is still in its infancy which undoubtedly leaves knowledge gaps in understanding the national burden of DFD. Future research should focus primarily on understanding the burden and extent of DFD. Population-based studies are urgently needed to better describe and understand the epidemiology of diabetic foot ulcers and lower limb amputations in Oman. The contribution and effectiveness of current diabetic foot services should also be evaluated regularly. 


\section{Conclusion}

This review highlights existing gaps in the provision of diabetic foot care in Oman. While initiatives to improve the quality of diabetes care have been implemented in recent years, the increase in the prevalence of diabetes in Oman indicates an urgent need for a national diabetes foot care programme with trained staff that integrates all levels of healthcare within the country. The ultimate target should be to significantly reduce the rate of diabetes-related lower limb amputations. This programme should be coupled with an organised monitoring system to enable examination of the epidemiology and impact of DFD in Oman.

\section{ACKNOWLEDGEMENTS}

The authors would like to thank the staff of the Department of Non-Communicable Diseases Surveillance \& Control, Directorate General of Health Affairs, $\mathrm{MOH}$, Oman, for providing some of the information and statistics used in this article.

\section{References}

1. Putting feet first in diabetes. Lancet 2005; 366:1674. doi: 10.10 16/S0140-6736(05)67672-6

2. International Diabetes Federation. IDF Diabetes Atlas, 7th ed. Watermael-Boitsfort, Belgium: International Diabetes Federation, 2015. Pp. 50-120.

3. Boulton AJ. The diabetic foot: Grand overview, epidemiology and pathogenesis. Diabetes Metab Res Rev 2008; 24:S3-6. doi: $10.1002 /$ dmrr.833.

4. Krans HMJ. Diabetes Care and Research in Europe: The St Vincent Declaration Action Programme - Implementation document, 2nd ed. Copenhagen, Denmark: WHO Regional Office for Europe, 1995. P. 8.

5. Boulton AJ, Vileikyte L, Ragnarson-Tennvall G, Apelqvist J. The global burden of diabetic foot disease. Lancet 2005; 366:1719-24. doi: 10.1016/S0140-6736(05)67698-2.

6. Ahmed AA, Elsharief E, Alsharief A. The diabetic foot in the Arab world. J Diabet Foot Complications 2011; 3:55-61.

7. Apelqvist J, Larsson J. What is the most effective way to reduce incidence of amputation in the diabetic foot? Diabetes Metab Res Rev 2000; 16:S75-83. doi: 10.1002/15207560(200009/10)16:1+<::AID-DMRR139>3.0.CO;2-8.

8. Al-Lawati JA, Panduranga P, Al-Shaikh HA, Morsi M, Mohsin N, Khandekar RB, et al. Epidemiology of diabetes mellitus in Oman: Results from two decades of research. Sultan Qaboos Univ Med J 2015; 15:e226-33.

9. Oman Ministry of Health. Diabetes Mellitus Management Guidelines for Primary Health Care, 2nd ed. Muscat, Oman: Ministry of Health, 2003

10. World Health Organization Regional Office for the Eastern Mediterranean. Country Cooperation Strategy for WHO and Oman: 2010-2015. From: www.who.int/countryfocus/ cooperation_strategy/ccs_omn_en.pdf Accessed: Mar 2016.

11. Bakker K, Apelqvist J, Schaper NC; International Working Group on Diabetic Foot Editorial Board. Practical guidelines on the management and prevention of the diabetic foot 2011. Diabetes Metab Res Rev 2012; 28:225-31. doi: 10.1002/ dmrr.2253.
12. Oman Ministry of Health. Diabetes foot clinical examination: Physical signs interpretation. Muscat, Oman: Ministry of Health, 2009.

13. Oman Ministry of Health. Annual Health Report 2002. From: www.moh.gov.om/en/web/statistics/annual-reports Accessed: Mar 2016.

14. Oman Ministry of Health. Annual Health Report 2003. From: www.moh.gov.om/en/web/statistics/annual-reports Accessed: Mar 2016.

15. Oman Ministry of Health. Annual Health Report 2004. From: www.moh.gov.om/en/web/statistics/annual-reports Accessed: Mar 2016.

16. Oman Ministry of Health. Annual Health Report 2005. From: www.moh.gov.om/en/web/statistics/annual-reports Accessed: Mar 2016.

17. Oman Ministry of Health. Annual Health Report 2006. From: www.moh.gov.om/en/web/statistics/annual-reports Accessed: Mar 2016

18. Oman Ministry of Health. Annual Health Report 2007. From: www.moh.gov.om/en/web/statistics/annual-reports Accessed: Mar 2016

19. Oman Ministry of Health. Annual Health Report 2008. From: www.moh.gov.om/en/web/statistics/annual-reports Accessed: Mar 2016

20. Oman Ministry of Health. Annual Health Report 2009. From: www.moh.gov.om/en/web/statistics/annual-reports Accessed: Mar 2016

21. Oman Ministry of Health. Annual Health Report 2010. From: www.moh.gov.om/en/web/statistics/annual-reports Accessed: Mar 2016.

22. Oman Ministry of Health. Annual Health Report 2011. From: www.moh.gov.om/en/web/statistics/annual-reports Accessed: Mar 2016

23. Oman Ministry of Health. Annual Health Report 2012. From: www.moh.gov.om/en/web/statistics/annual-reports Accessed: Mar 2016

24. Oman Ministry of Health. Annual Health Report 2013. From: www.moh.gov.om/en/web/statistics/annual-reports Accessed: Mar 2016.

25. van Houtum WH, Rauwerda JA, Ruwaard D, Schaper NC, Bakker K. Reduction in diabetes-related lower-extremity amputations in the Netherlands: 1991-2000. Diabetes Care 2004; 27:1042-6. doi: 10.2337/diacare.27.5.1042.

26. Peek ME. Gender differences in diabetes-related lower extremity amputations. Clin Orthop Relat Res 2011; 469:1951-5. doi: 10.1007/s11999-010-1735-4.

27. Larsson J, Eneroth M, Apelqvist J, Stenström A. Sustained reduction in major amputations in diabetic patients: 628 amputations in 461 patients in a defined population over a 20-year period. Acta Orthop 2008; 79:665-73. doi: 10.10 $80 / 17453670810016696$.

28. Canavan RJ, Unwin NC, Kelly WF, Connolly VM. Diabetesand nondiabetes-related lower extremity amputation incidence before and after the introduction of better organized diabetes foot care: Continuous longitudinal monitoring using a standard method. Diabetes Care 2008; 31:459-63. doi: 10.2337/dc071159.

29. Alshishtawy MM. Four decades of progress: Evolution of the health system in Oman. Sultan Qaboos Univ Med J 2010; $10: 12-22$.

30. Anwar H, Fischbacher CM, Leese GP, Lindsay RS, McKnight JA, Wild SH, et al. Assessment of the under-reporting of diabetes in hospital admission data: A study from the Scottish Diabetes Research Network Epidemiology Group. Diabet Med 2011; 28:1514-19. doi: 10.1111/j.1464-5491.2011.03432.x. 
31. Al-Hinai SS, Al-Busaidi AS, Al-Busaidi IH. Medical tourism abroad: A new challenge to Oman's health system - Al Dakhilya region experience. Sultan Qaboos Univ Med J 2011; 11:477-84.

32. Singh N, Armstrong DG, Lipsky BA. Preventing foot ulcers in patients with diabetes. JAMA 2005; 293:217-28. doi: 10.1001/ jama.293.2.217.

33. Oman Ministry of Health. Operational and Management Guidelines for the National Non-Communicable Diseases Screening Program. Muscat, Oman: Ministry of Health, 2009.

34. Oman Ministry of Health. Policy on quality improvement of diabetes care. Muscat, Oman: Ministry of Health, 2009.

35. Oman Ministry of Health representatives. Personal communications, 2015.

36. Plank J, Haas W, Rakovac I, Görzer E, Sommer R, Siebenhofer A, et al. Evaluation of the impact of chiropodist care in the secondary prevention of foot ulcerations in diabetic subjects. Diabetes Care 2003; 26:1691-5. doi: 10.2337/diacare.26.6.1691.

37. Hämäläinen $\mathrm{H}$, Rönnemaa $\mathrm{T}$, Toikka $\mathrm{T}$, Liukkonen $\mathrm{I}$. Long-term effects of one year of intensified podiatric activities on foot-care knowledge and self-care habits in patients with diabetes. Diabetes Educ 1998; 24:734-40. doi: $10.1177 / 014572179802400609$.

38. Unwin N. The diabetic foot in the developing world. Diabetes Metab Res Rev 2008; 24:S31-3. doi: 10.1002/dmrr.857.

39. Al-Busaidi IS, Coppell KJ, Abdulhadi N. The quality of foot care amongst Omani diabetic patients attending primary health care facilities in Muscat, Oman: A pilot study. Paper presented at the 5th Annual Conference of the Otago International Health Research Network, Dunedin, New Zealand, 7-8 Nov 2012.
40. Elliott JA, Abdulhadi NN, Al-Maniri AA, Al-Shafaee MA, Wahlström R. Diabetes self-management and education of people living with diabetes: A survey in primary health care in Muscat Oman. PLoS One 2013; 8:e57400. doi: 10.1371/journal. pone. 0057400

41. Al Shafaee MA, Al-Shukaili S, Rizvi SG, Al Farsi Y, Khan MA, Ganguly SS, et al. Knowledge and perceptions of diabetes in a semi-urban Omani population. BMC Public Health 2008; 8:249. doi: 10.1186/1471-2458-8-249.

42. Noor Abdulhadi NM, Al-Shafaee MA, Wahlström R, Hjelm K. Doctors' and nurses' views on patient care for type 2 diabetes: An interview study in primary health care in Oman. Prim Health Care Res Dev 2013; 14:258-69. doi: 10.1017/ S146342361200062X.

43. Ramachandran A. Specific problems of the diabetic foot in developing countries. Diabetes Metab Res Rev 2004; 20:S19-22. doi: $10.1002 /$ dmrr.440

44. Thomson FJ, Veves A, Ashe H, Knowles EA, Gem J, Walker MG, et al. A team approach to diabetic foot care: The Manchester experience. The Foot 1991; 2:75-82. doi: 10.1016/09582592(91)90034-9.

45. Pedrosa HC, Leme LA, Novaes C, Saigg M, Sena F, Gomes EB, et al. The diabetic foot in South America: Progress with the Brazilian Save the Diabetic Foot Project. Int Diabetes Monit 2004; 16:10-17.

46. van Houtum WH. Barriers to the delivery of diabetic foot care. Lancet 2005; 366:1678-9. doi: 10.1016/S0140-6736(05)67675-1. 